\title{
Acoustic Characterization of Compact Jet Engine Simulator Units
}

\author{
Michael J. Doty ${ }^{1}$ and Henry H. Haskin ${ }^{2}$ \\ NASA Langley Research Center, Hampton, VA, 23681
}

\begin{abstract}
Two dual-stream, heated jet, Compact Jet Engine Simulator (CJES) units are designed for wind tunnel acoustic experiments involving a Hybrid Wing Body (HWB) vehicle. The newly fabricated CJES units are characterized with a series of acoustic and flowfield investigations to ensure successful operation with minimal rig noise. To limit simulator size, consistent with a 5.8\% HWB model, the CJES units adapt Ultra Compact Combustor (UCC) technology developed at the Air Force Research Laboratory. Stable and controllable operation of the combustor is demonstrated using passive swirl air injection and backpressuring of the combustion chamber. Combustion instability tones are eliminated using nonuniform flow conditioners in conjunction with upstream screens. Through proper flow conditioning, rig noise is reduced by more than $20 \mathrm{~dB}$ over a broad spectral range, but it is not completely eliminated at high frequencies. The low-noise chevron nozzle concept designed for the HWB test shows expected acoustic benefits when installed on the CJES unit, and consistency between CJES units is shown to be within $0.5 \mathrm{~dB}$ OASPL.
\end{abstract}

\section{Nomenclature}
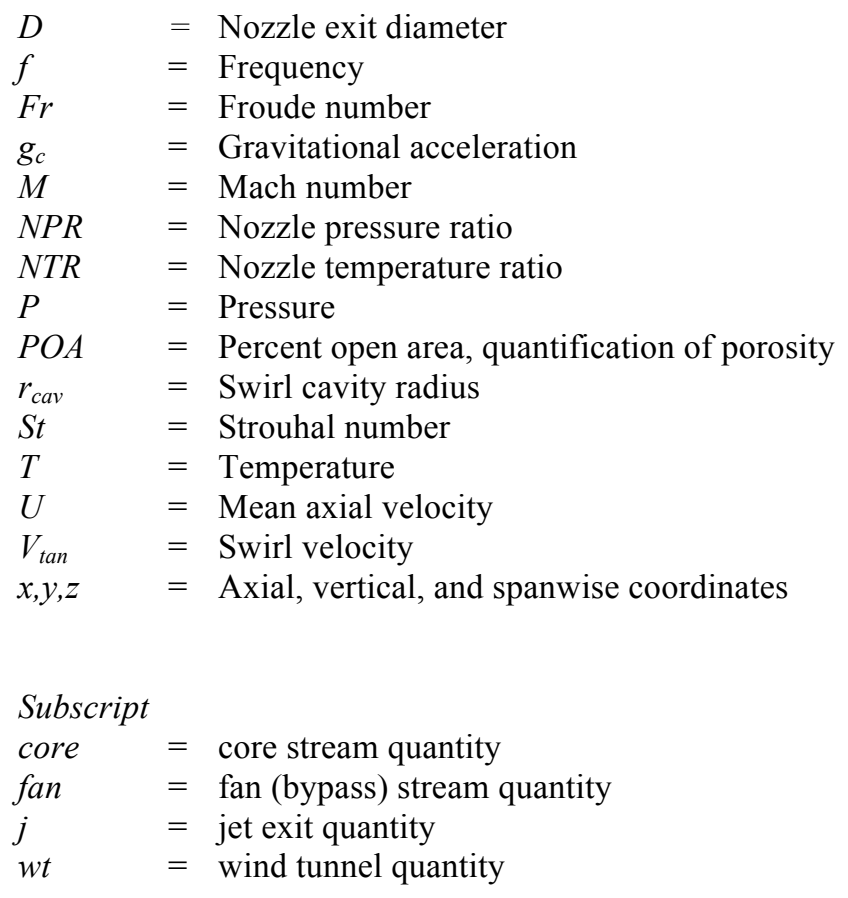

\footnotetext{
${ }^{1}$ Research Aerospace Engineer, Aeroacoustics Branch, Mail Stop 461, Senior Member AIAA.
}

${ }^{2}$ Engineer, Aeroacoustics Branch, Mail Stop 166. 


\section{Introduction}

Tet noise continues to be an important, if not dominant, source of noise for most commercial and military aircraft. Its effects can cause annoyance in communities surrounding airports and military bases, potential hearing loss for personnel consistently working on aircraft carrier decks, and even structural fatigue of aircraft components in close proximity to jet exhausts. In an effort to better understand and reduce jet noise, experiments have been performed for several decades in a multitude of facilities around the world. Some of the largest industry and government jet noise facilities, references ${ }^{1-5}$ among others, have the capability to simulate a typical jet engine cycle point (hot core stream, warm fan stream) in an anechoic wind tunnel environment. The jet engine simulator portion of these facilities is carefully designed to include sufficient length for proper combustion, flow conditioning, and rig noise attenuation. In addition, pipe diameters and plenum sections are generally kept as large as possible to minimize flow velocities leading to the nozzle section. Ahuja ${ }^{6}$ offers guidelines that, if closely followed, can result in an acoustically clean facility with minimal internal rig noise. The jet rig improvements and strategies documented by Vishwanathan ${ }^{7}$ provide an example put into practice.

New challenges, however, are introduced if one is interested in incorporating an airframe near the jet flow to study acoustic shielding and interaction effects. Jet noise facilities typically have limited wind tunnel areas; therefore, the choice of an airframe section that is fully in the wind tunnel flow yet properly scaled to the jet nozzle can be particularly difficult. In addition, a robust support structure is usually required for the airframe, but such a structure needs to be minimally disruptive to the anechoic environment of the facility. Furthermore, accurate axial and vertical positioning of the airframe relative to the jet nozzle can be problematic because large jet plenums can limit the proximity of an airframe section to the nozzle exit plane. For instance, to approximate the full-scale vertical offset distance from the nozzle centerline to the airframe surface, Czech et al. ${ }^{8}$ used a nozzle extension to avoid upstream interference. This method worked well in testing a planform representing the aft airframe section but becomes more difficult if a full airframe model test is desired.

An alternative approach is to place a modular jet engine simulator in an existing large-scale anechoic wind tunnel facility. This is the method chosen for the Hybrid Wing Body (HWB) acoustic test within the 14-by 22-Foot Subsonic Tunnel at NASA Langley Research Center. In this case, the goals of system level noise assessment and investigation of shielding effects for advanced vehicle concepts require two dual-stream, heated jet, simulators to be placed in close proximity to a three-dimensional airframe model of $5.8 \%$ scale. The challenges with this approach are different from those previously discussed and are associated with effectively shrinking two jet engine simulators rather than placing and supporting the airframe model. To maintain consistent scaling with the 12.4-ft wingspan, traditional jet engine simulators (typically $7-10$ feet long) do not work. Furthermore, to enable the modularity and flexibility of two jet engine simulator units to move either with the model or independent of the model requires a very compact design. Delivery pipe diameters and plenum areas need to be as small as possible to enable accurate representation of the standoff distance between the jet centerlines and the model surface. Lastly, long stretches of straight pipe, beneficial for minimizing rig noise, are not possible in this case.

The resulting Compact Jet Engine Simulator (CJES) units shown in Fig. 1 are the product of several design iterations and represent a dramatic decrease in size compared to current jet engine simulators such as the jet engine simulator (JES) within the Low Speed Aeroacoustic Wind Tunnel (LSAWT) as seen in Fig. 2. The design philosophy is to exactly match the model scale at the nozzle exit, to minimize the radial and axial increases beyond a scaled nacelle elsewhere, and to balance the size requirements with the need to preserve low rig noise. A key component permitting the smaller scale simulators is the use of Ultra Compact Combustor (UCC) technology adapted from Zelina et al. ${ }^{9}$ at the Air Force Research Lab (AFRL). The UCC employs injected swirl air to promote mixing with the injected fuel. The mixture is burned in a circumferential cavity. The high centrifugal loading enhances reaction rates and reduces the combustion volume as first described by Lewis ${ }^{10}$. The application of this technology to the current CJES requires the additional consideration of acoustics, which was not a primary factor in the AFRL design. Therefore, careful selection and placement of flow conditioners is important in minimizing combustion noise and rig noise, and a previous risk reduction study ${ }^{11}$ provides guidance. 


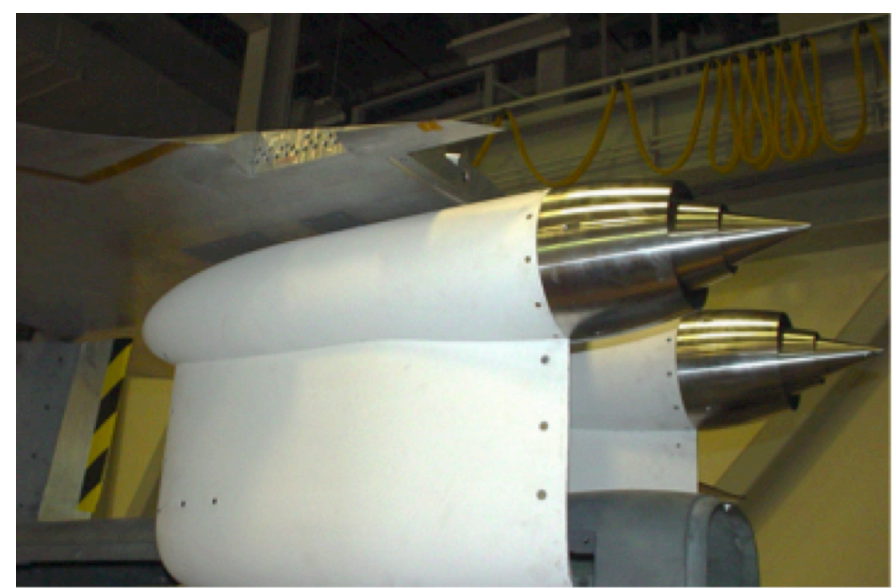

Figure 1. Compact Jet Engine Simulator (CJES) units mounted underneath a portion of the HWB airframe model.

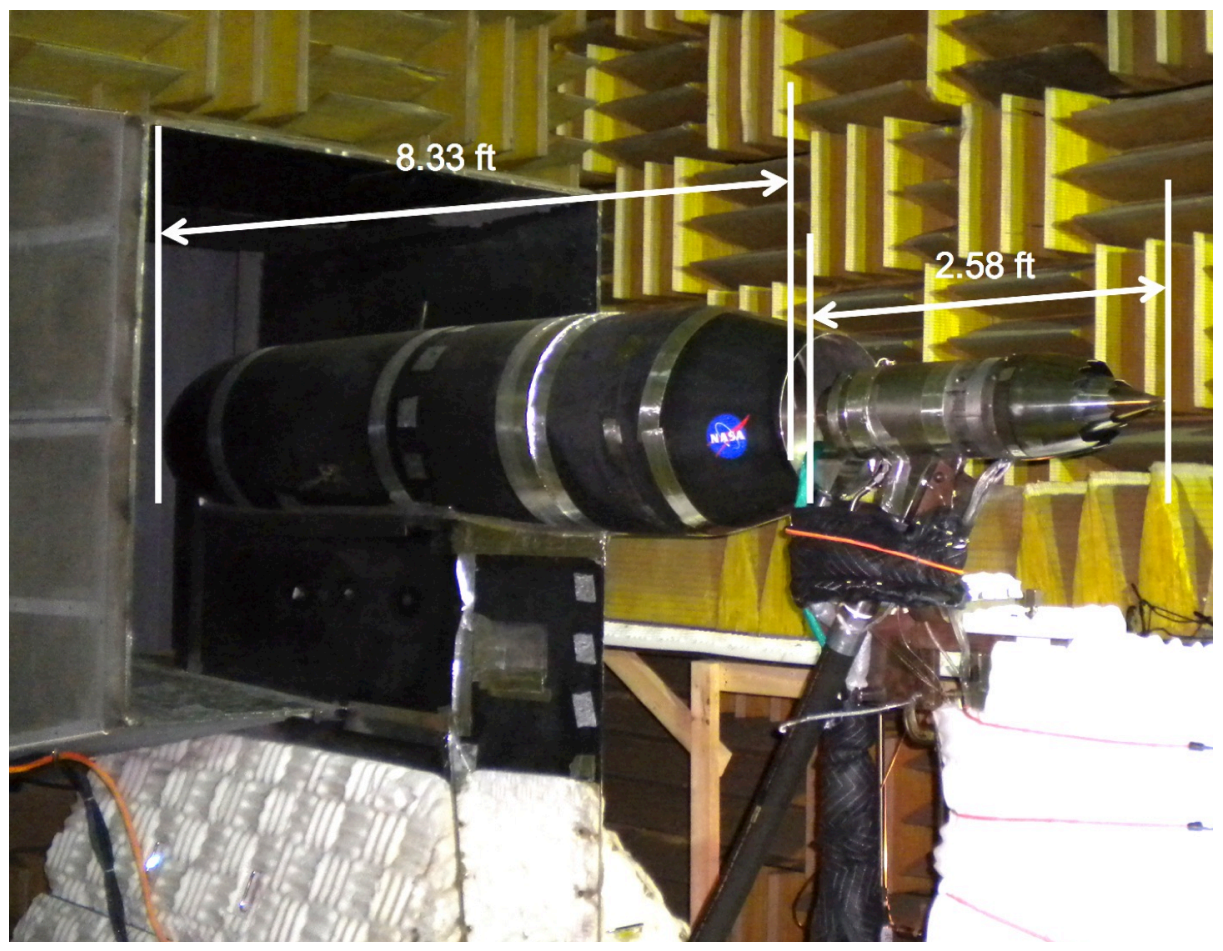

Figure 2. The compact nature of the CJES unit ( $2.58 \mathrm{ft})$ compared to the JES ( $8.33 \mathrm{ft})$.

The current study describes the efforts to characterize the acoustic and aerodynamic properties of the initial UCC and then the full CJES units in the LSAWT facility prior to entry into the 14-by 22-Foot Subsonic Tunnel. Modifications and acoustic assessments are shown that contribute to the simultaneous goals of stable operation and minimal rig noise. The next section of this paper describes the facility, the CJES hardware, the instrumentation, and the data acquisition/processing in greater detail. Section III discusses the experimental results that include the flowfield measurements used to optimize the swirl combustor, as well as the acoustic measurements used to diagnose combustion instability tones, investigate rig noise, assess the effects of two different nozzle systems, and compare the two CJES units' noise signatures. Lastly, Section IV concludes the discussion with a summary of the results. 


\section{Experimental Procedures}

\section{A. Facility}

The CJES acoustic characterization experiments took place in the LSAWT facility shown in Fig. 3. The LSAWT is comprised of a $17.5 \mathrm{ft}$ high $\times 17 \mathrm{ft}$ wide $\mathrm{x} 34 \mathrm{ft}$ long anechoic chamber surrounding an open jet wind tunnel and a dual stream jet engine simulator (JES). Forward flight is simulated with the wind tunnel using a $4.7 \mathrm{ft} x$ $4.7 \mathrm{ft}$ free jet capable of speeds up to Mach 0.32. The JES was not used for the current experiments, but the fan stream outer shell was attached to minimize separation upstream of the installed CJES unit. The CJES unit was placed on a support stand elevating it to the same height as the JES centerline as can be seen in Fig. 2. The CJES centerline was required to be displaced 2.875 " to the side of the JES centerline to accommodate the pallet containing the air and fuel supply valves.

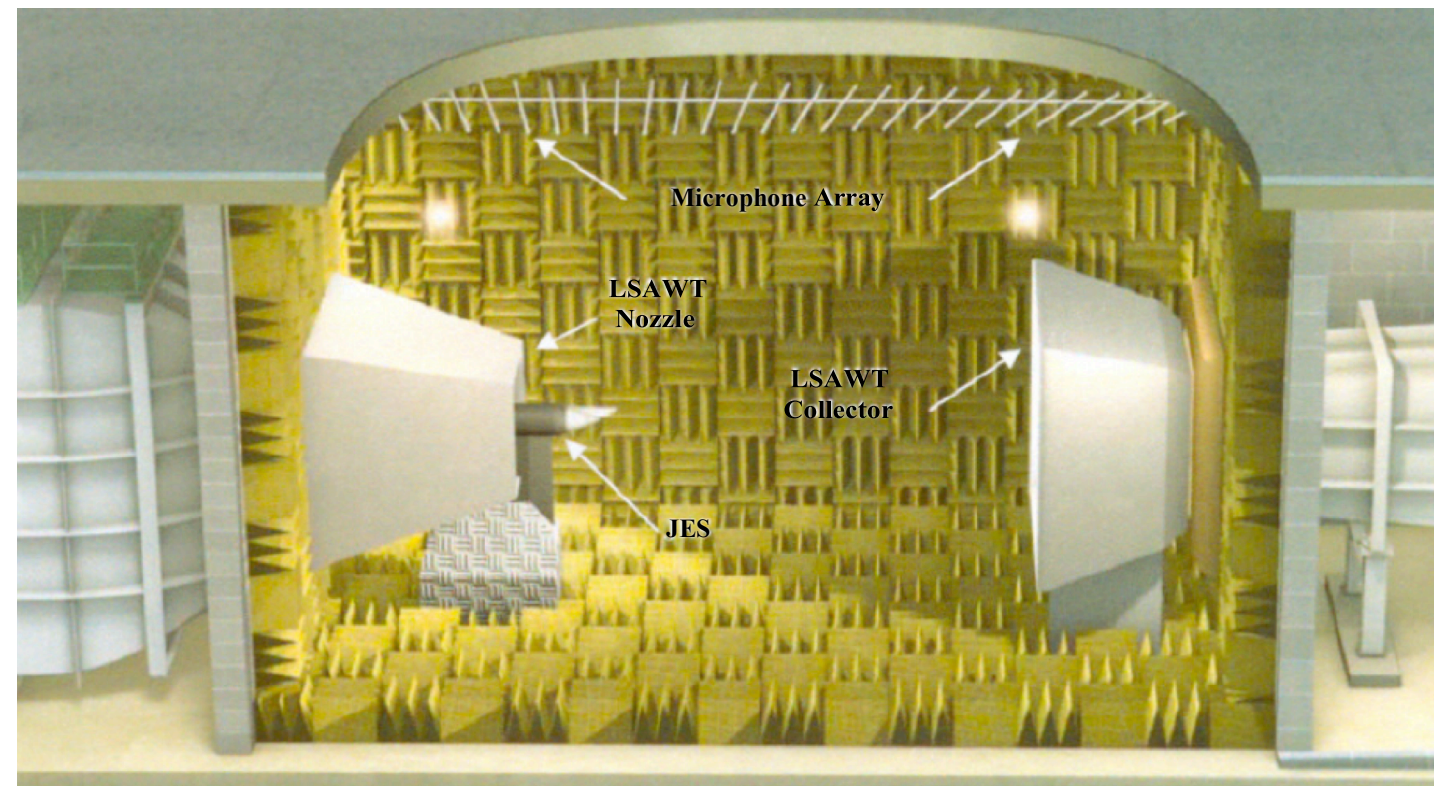

Figure 3. NASA Langley Low Speed Aeroacoustic Wind Tunnel.

\section{B. CJES Units}

A schematic of a single CJES unit is shown in Fig. 4a. Each unit is designed with capability to run over a bypass ratio range from 5 to 15 when connected to the $14 \times 22$ compressed air supply system, though achieving bypass ratio 15 would require some additional fan plenum modifications. The CJES units are currently configured for a bypass ratio 10 cycle, to deliver up to approximately $8 \mathrm{lbm} / \mathrm{s}$ of fan stream airflow at temperatures up to $150^{\circ} \mathrm{F}$ and almost $1 \mathrm{lbm} / \mathrm{s}$ of core stream airflow at temperatures up to $1500^{\circ} \mathrm{F}$. Air is supplied through two-inch flexible rubber hoses for each stream. Because of the modularity of the CJES units, the mass flow limits vary, depending on the supply air system and delivery piping to which they are attached. In fact, the initial supply pressure limitations at the LSAWT facility required some facility piping modifications to achieve successful operation at all desired setpoints.

Also shown in Fig. $4 \mathrm{~b}$ is the charging station that consists of two temperature rakes of 4 thermocouples each for the core stream and 5 thermocouples each for the fan stream. Likewise, two total pressure rakes of 4 ports each for the core stream and 5 ports each for the fan stream are included, with an additional port at the tip of the charging station centerbody. In total, 19 total pressure ports and 18 total temperature probes are contained in the CJES charging station, as well as two static pressure ports in each of the core and fan streams. The outputs of these total probes are analyzed individually to assess flow uniformity and are averaged together for use in determining nozzle pressure ratio (NPR) and nozzle temperature ratio (NTR). 


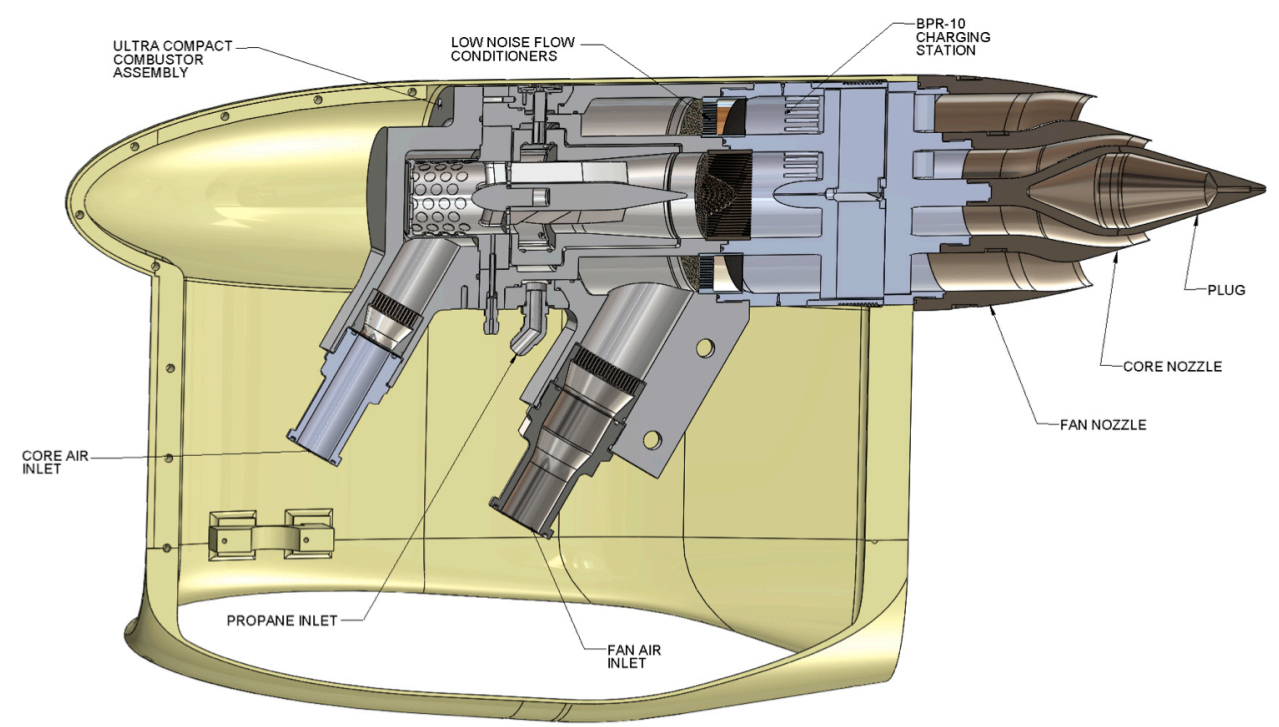

a)

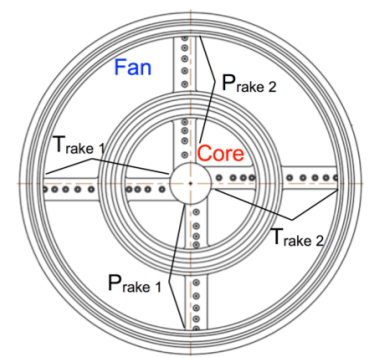

b)

Figure 4. Schematic of a) CJES unit and b) charging station.

The fuel delivery system for the CJES units includes a vaporizer for conversion of liquid propane to gaseous propane. In addition, a nitrogen-purged containment vessel for each CJES unit encases all fuel delivery control valves to ensure safe operation in the $14 \times 22$ environment, which has not previously operated with combustible products. Figure 5 shows one of these fuel valve pallets, which also contains the valving for the core and fan air streams (not visible) and the Programmable Logic Controller (PLC) cabinet. A 0.5" flexible rubber hose supplies the gaseous propane to the CJES unit where it is injected through six capped, cross-drilled fuel injectors (0.035" hole diameter). These fuel injectors are mounted in separate circumferential flame-holder grooves recessed around the 2.84" outer diameter of the swirl air cavity of the UCC as shown in Fig. 6. The fuel mixes with the swirl air injected through 24 ports of $0.20^{\prime}$ diameter angled at $45^{\circ}$ around the cavity. The mixture is ignited by a single ceramic igniter that can be turned off once the mixture is burning.

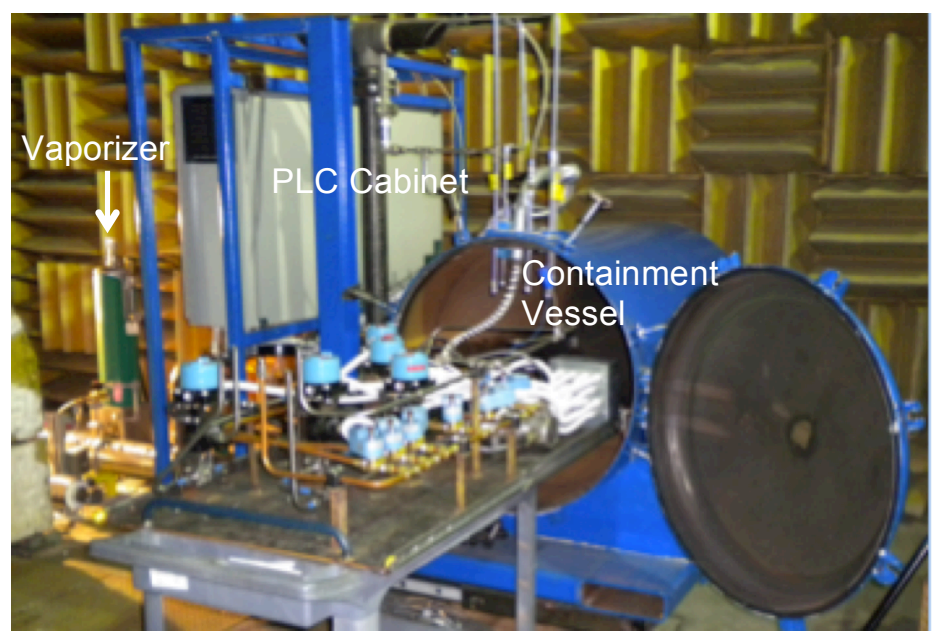

Figure 5. Fuel valve pallet including propane delivery containment vessel within the LSAWT. 


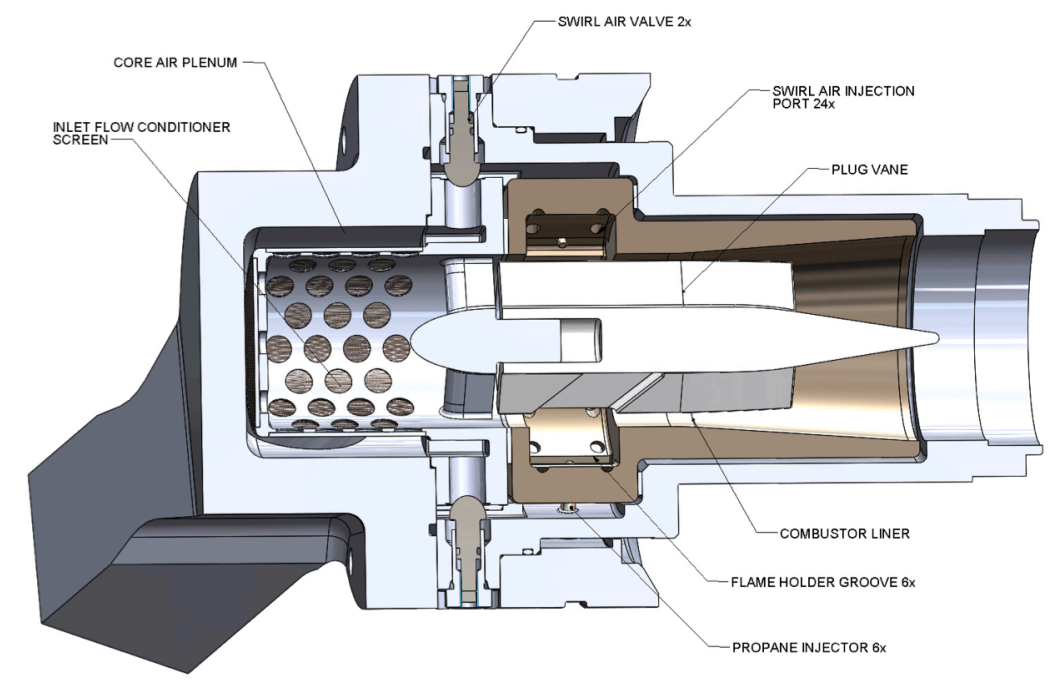

Figure 6. Schematic of the Ultra Compact Combustor (UCC) section of the CJES .

Each CJES unit is fabricated primarily from Inconel 625 and 303 stainless steel. The exception is the combustor liner, which was originally a cast ceramic piece, but due to robustness issues, was subsequently replaced with a laser-sintered cobalt-chromium liner. The combustor plug-vane assembly and core downstream flow conditioner are also laser-sintered cobalt-chromium components.

Two sets of convergent core and fan nozzles accompany each CJES unit - one set is axisymmetric while the other set includes an essentially uniform core chevron nozzle and an asymmetric fan chevron nozzle, designed based on extensive testing described by Thomas et al. ${ }^{12}$ A separate plug for the core stream also accompanies each set of nozzles. The core nozzle diameter is 3.28 inches and the fan nozzle diameter is 6.21 inches.

\section{Instrumentation}

1. Pressure Transducers and Thermocouples for Flowfield Measurements

The CJES combustor was fitted with an instrumented fixture plate including 1 total pressure probe and 5 Type K thermocouples with Inconel sheaths (0.062" diameter) for use in assessing its operational characteristics prior to the assembly of the CJES charging station and nozzle system. The pressure probe was used to get preliminary indications of flow velocity, and prior experience with facility air supply valve settings was used as a check on mass flow rates. The thermocouples at the exit of the combustor permitted initial temperature distribution checkouts. In addition, to measure the swirl velocity profile within the swirl cavity of the combustor, a Pitot probe (Fig. 7) was manufactured to fit directly into the igniter orifice during initial unheated operations. The pressure ports were connected to a Pressure Systems 8400 ESP Pressure Scanner ( \pm 45 psid).

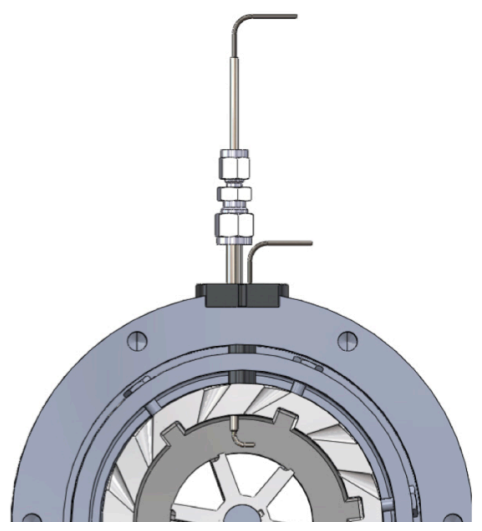

Figure 7. Pitot-static probe to determine swirl velocity within swirl cavity. 


\section{Far-Field Microphones}

The LSAWT linear array of 28 B\&K Model 4939 free-field microphones of 0.25 -inch diameter was used to measure far-field noise characteristics in conjunction with Model 2670 pre-amplifiers and 8 B\&K Type 28294 channel power supplies. The angular range of the microphone positions was from $40^{\circ}$ to $150^{\circ}$ from the upstream jet axis. After accounting for the previously mentioned horizontal displacement of the CJES centerline relative to the standard JES centerline, the microphones were located on an azimuthal angle of $49.1^{\circ}$ above the sideline and 140.4 inches away from the jet centerline pointed approximately toward the jet exit plane. Electrostatic and pistonphone calibrations were routinely performed on all microphones, and the grid caps were removed prior to testing.

\section{Data Acquisition and Processing}

The LSAWT data acquisition system (DAS) consists of a series of LabVIEW virtual instruments running on an acquisition PC. The steady-state pressure transducer and thermocouple signals were averaged over 8 seconds while the test point was maintained within $0.5 \%$ for NPR and within $1 \%$ for NTR. The 28 dynamic signals for the linear microphone array were fed through high pass $(100 \mathrm{~Hz})$ and low pass $(102,300 \mathrm{~Hz})$ signal conditioning filters from Precision Filters Inc. and into 4 National Instruments NI-PXI 6143 simultaneous sampling multifunction DAQ boards. Data were sampled at $210 \mathrm{kHz}$ with 180 data averages, resulting in a 4096-point spectrum with a frequency resolution of $25.63 \mathrm{~Hz}$. Microphone actuator and free-field response corrections were applied; atmospheric attenuation corrections to a lossless condition were applied according to the ANSI standard ${ }^{13}$; and background noise subtraction and shear layer corrections using Amiet's method ${ }^{14}$ were applied when the flight stream was operating. The corrected far-field spectral levels were then propagated to a one-foot arc, and frequencies were nondimensionalized to Strouhal number:

$$
S t=\frac{f}{\left(U_{j} / D_{j}\right)}
$$

In the current work at BPR 10, nondimensionalization is with respect to the fan stream jet velocity and fan nozzle diameter unless otherwise noted. Finally, spectral levels were adjusted to $1 \mathrm{~Hz}$ common bandwidth and to a per unit Strouhal number basis for consistency with the frequency nondimensionalization according to

$$
S P L(d B \text { per unit } S t \#)=S P L+10 \log _{10}\left(\frac{U_{j} / D_{j}}{\Delta f}\right),
$$

with $\Delta f$ referring to the original frequency bandwidth noted previously. These corrections have been applied to all microphone data unless otherwise noted.

\section{Experimental Results}

\section{A. Flow Conditions}

The flow conditions examined in this work are focused on the approach, cutback, and takeoff (sideline) cycle points of the HWB that will be simulated using the two dual-stream CJES units. Table 1 describes these flow conditions in more detail. Note that a change to the HWB flight profile during the CJES acoustic characterization experiments led to an update in both the approach and the cutback cycle points. The approach cycle point is of lower priority than the cutback and takeoff points for two reasons. First, the relatively low throttle setting (particularly for the HWB) results in jet noise levels that are much lower than other aircraft noise sources such as the airframe. Second, these low jet noise levels are very difficult to accurately measure given the background noise of the flight stream. While this is the case for the $14 \times 22$ test, the phased array capability is expected to discern these low jet noise levels more effectively than single microphone measurements. Thus, the approach condition is a part of the current test matrix, albeit at a lower priority. 
Table 1. Typical experimental conditions assuming standard day conditions.

\begin{tabular}{|c|c|c|c|c|c|c|}
\hline $\boldsymbol{N P R}_{\text {core }}$ & $\boldsymbol{N T R}_{\text {core }}$ & $\boldsymbol{N P R}_{\text {fan }}$ & $\boldsymbol{N T R}_{\text {fan }}$ & $\boldsymbol{f}_{\boldsymbol{c}}=\boldsymbol{U}_{\boldsymbol{j}} / \boldsymbol{D}_{\boldsymbol{j}}(\mathbf{H z})$ & $\boldsymbol{M}_{\boldsymbol{w} \boldsymbol{t}}$ & $\boldsymbol{H W B}_{\boldsymbol{B}}$ Cycle point \\
\hline 1.034 & 2.088 & 1.117 & 1.037 & 867 & $0.10,0.17$ & Updated Approach \\
\hline 1.048 & 2.217 & 1.158 & 1.049 & 1001 & $0.10,0.17$ & Approach \\
\hline 1.240 & 2.721 & 1.461 & 1.124 & 1639 & $0.10,0.17,0.23$ & Updated Cutback \\
\hline 1.285 & 2.792 & 1.508 & 1.135 & 1710 & $0.10,0.17,0.23$ & Cutback \\
\hline 1.411 & 2.956 & 1.607 & 1.161 & 1850 & $0.10,0.17,0.23$ & Takeoff \\
\hline
\end{tabular}

\section{B. Flowfield Measurements}

Achieving consistent operation of the CJES units at the desired setpoints requires successful ignition, stability, and controllability of the Ultra Compact Combustor. Therefore, before the full CJES unit was tested, a significant amount of time was dedicated to proving safe and consistent operation of the UCC. The instrumented fixture plate described in Section IIC was used to establish flow conditions, and a video camera mounted in the wind tunnel diffuser was used to provide a qualitative indication of uniformity of combustion within the swirl cavity. A series of experiments documenting airflow, fuel flow, and time to ignition eventually led to repeatable ignition settings.

To achieve stable combustion, it became apparent that the proper amount of injected swirl air was a key parameter. While the AFRL combustor ${ }^{9}$ uses a separate swirl air supply with controllable pressure, for simplicity the CJES combustor makes use of an inlet flow conditioner screen (Dynapore High Flow Media HFM 600). The flow conditioner screen provides backpressure in a core air plenum and passive control of the amount of swirl air entering the swirl cavity as shown in Fig. 6. In addition, two 0.5 -inch swirl air valves are used to meter the flow manually. Several swirl air valve settings were investigated during the course of the combustor checkout testing. Fig. 8a shows an example (looking upstream into the exit of the UCC) in which not enough swirl air is present for the axial flow, and the flame travels downstream with the plug acting as the flameholder. On the other hand, Fig. 8b shows that proper swirl air settings (valves fully open) lead to desired combustion in which the flame is relatively stationary within the swirl cavity at the upstream base of the plug-vane assembly.

AFRL studies ${ }^{9}$ indicate an optimum swirl air mass fraction of approximately $20 \%$ of the axial flow. Furthermore, a centrifugal loading of $F r=3000$ or higher was suggested for stable combustion", where $\mathrm{Fr}$ is the Froude number defined as

$$
F r=\frac{V_{t a n}^{2}}{g_{c} r_{c a v}},
$$

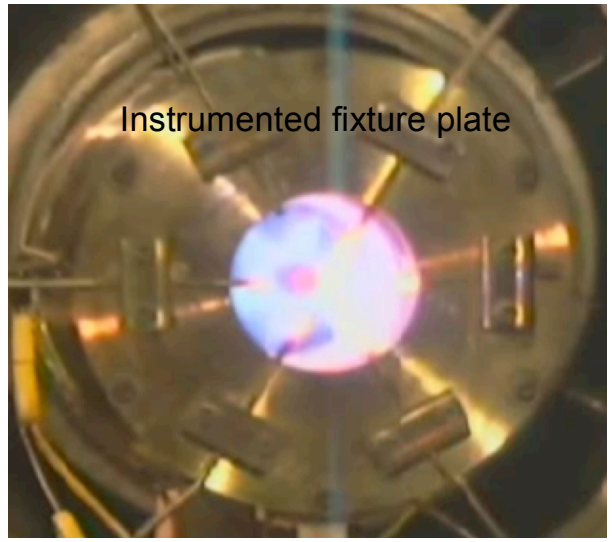

a)

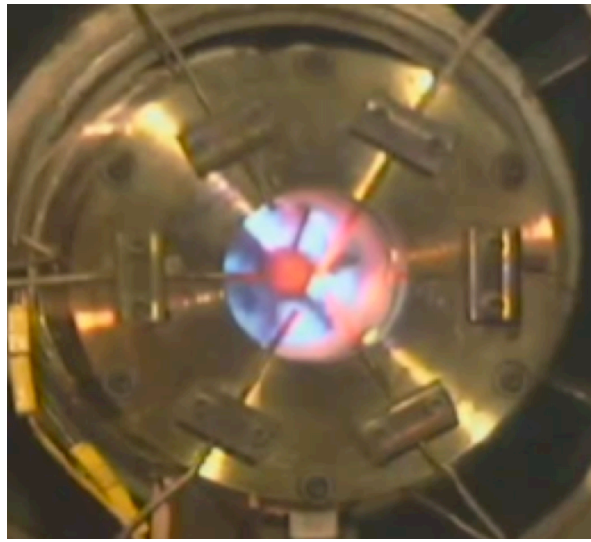

b)

Figure 8. a) Inadequate levels of swirl air injection lead to flame migrating downstream of the swirl cavity to plug tip, and b) stable combustion within swirl cavity is observed with proper swirl air injection.

\footnotetext{
${ }^{*}$ H. Haskin private communication with J. Zelina, July 2012.
} 
and $V_{\tan }$ refers to the tangential (swirl) velocity, $g_{c}$ refers to gravitational acceleration, and $r_{c a v}$ refers to the average cavity radius ${ }^{15}$. To optimize the current CJES combustor, a swirl velocity probe was designed by using a Pitot-static tube that could be inserted radially through the hole normally reserved for the igniter assembly, as previously shown in Fig. 7. Determination of swirl velocity during unheated operations was then possible.

Figure 9a shows the swirl velocity profile within the swirl cavity for a core stream operating condition near approach. The probe was positioned along the outer edge of the swirl cavity and moved inward until contact was made with the plug-vane assembly. Note that as more run time was accrued on the ceramic combustor liners, they tended to crack, creating leak paths and decreasing the swirl air velocity as shown in Fig. 9a. Figure $9 \mathrm{~b}$ shows the corresponding centrifugal loading profile, calculated according to Eq. (3), but using the local radial value for each point. These measurements, all with swirl metering valves fully open, show that sufficient swirl is attained $(F r \geq$ 3000) only when the liner is free of cracks that permit leaks. Ultimately, a cobalt-chromium, laser-sintered combustor liner replaced the ceramic liner to minimize further cracking and leaking issues. Increasing jet operating pressure leads to a corresponding increase in backpressure in the core plenum supplying the swirl air. In turn, an acceptable mass fraction of swirl air for stable combustion is maintained over the entire operating range with one swirl air valve setting. Thus, manual adjustments to the swirl air valves were not necessary during acoustic testing.

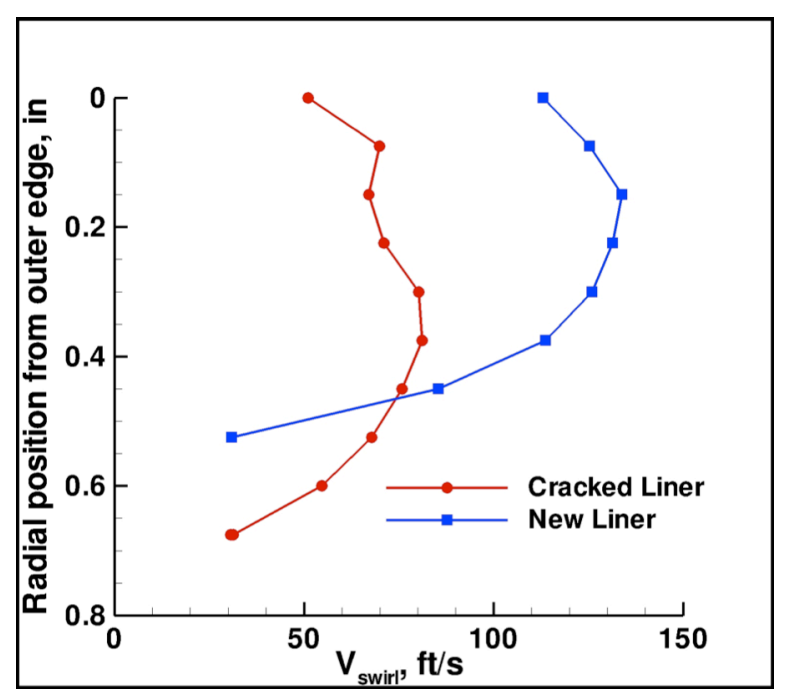

a)

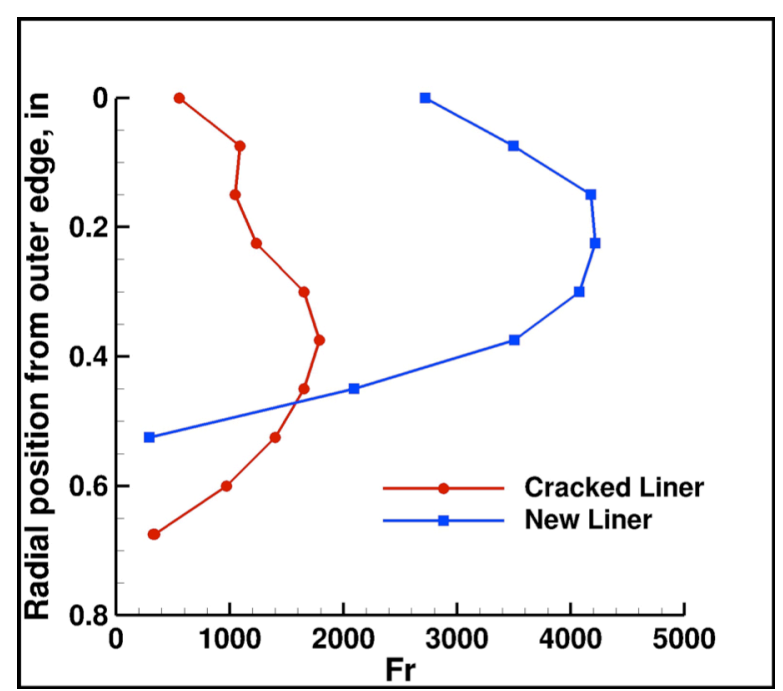

b)

Figure 9. a) Swirl velocity measurements within the swirl cavity and corresponding b) Froude number for both a cracked and a new combustor liner.

After addressing the ignition and stability issues of the UCC, controllability was the remaining operational hurdle. The flame tended to blow out with increasing jet velocity, regardless of swirl air valve setting. Insufficient backpressure within the combustor was suspected because the AFRL design ${ }^{16}$ had a significantly larger combustor centerbody (1.95" diameter) providing backpressure compared to the current centerbody design ( 0.9 " diameter). However, the current combustor was designed with noise as a primary consideration; thus, the intention was to backpressure the exit of the combustor with a downstream flow conditioner to slow down the combustor velocity, increase flow uniformity, and decrease the noise. Although optical access would no longer be possible, it was decided to move forward with the downstream flow conditioner testing to see the effects of the additional backpressure on controllability. A combination of laser-sintered cobalt-chromium honeycomb disks and stainless steel fine mesh screens were examined based on a previous investigation ${ }^{11}$. The additional backpressure generated within the combustor section (typically 30-100 psia, depending on flow condition) did solve the controllability issue, in that combustion was now maintainable when moving to higher cycle points. However, too much backpressure also proved problematic. If the backpressure increased to a level close to that of the fuel injection pressure $(\sim 140$ psia), a decrease in temperature control authority was observed, as well as significant coking of unmixed propane near the fuel injectors. Lastly, the stainless steel fine mesh was not sufficiently robust to consistently withstand the temperatures of the core flow. Therefore, a 0.5 " thick honeycomb disk of 32.5 percent open area (POA) with 0.056 " face-face hexagonal size was selected as the primary candidate for further checkout. 


\section{Acoustic Measurements}

\section{Combustion Instabilities}

Having established consistent operation of the UCC, the team proceeded to the next CJES checkout phase investigation of the far-field acoustics. Although preliminary acoustic measurements were made with just the UCC, more representative acoustic measurements are possible with the full CJES unit assembled around the UCC. This is because the cycle point is more reliably set using the charging station instrumentation shown in Fig. $4 \mathrm{~b}$, and the termination of the jet becomes a properly backpressured dual stream nozzle exit rather than a blunt-faced fixture plate affixed to the end of the combustor exhaust duct.

Preliminary operation of both the core and the fan streams of the full CJES unit revealed that the inlet piping to the CJES fan stream was too restrictive to provide the required mass flow rates with the existing LSAWT supply pressure limitations. Note that the CJES was designed with the higher $14 \times 22$ supply pressure limits in mind. This issue was later remedied with some rearrangement and recertification of the LSAWT supply piping. In the meantime, acoustic measurements necessarily focused only on the CJES core stream.

Acoustic measurements at higher setpoints revealed jet noise acoustic spectra that were dominated by a tone at $S t=0.18$, which corresponds to $820 \mathrm{~Hz}$, and its associated harmonics, as seen in Fig. 10. These plots show far-field spectra at $90^{\circ}$ and near $140^{\circ}$ from the jet inlet axis with the core stream operating at the takeoff condition and the fan stream providing a minimal amount of cooling air around the core $\left(N P R_{f a n}=1.02\right)$. Spectra are nondimensionalized as discussed in Section IID, but based on the core stream for this particular case. The tone was typically in excess of $25 \mathrm{~dB}$ above broadband levels and was audible even outside of the building. After a thorough system leak check and additional testing at various temperatures and pressures, the tone could be traced to the combustion process. In fact, the combustion-driven acoustic instability resulted from a resonant interaction between the heat release and airflow within the combustor cavity and the length of the combustor section. Much like a Sondhauss tube ${ }^{17}$, it was found that the quarter wavelength of the tone frequency was closely related to the combustor length. In fact, by switching the downstream flow conditioner and spacer ring positions, and effectively changing the length of the combustor, the tone frequency was altered in a corresponding manner. Nonetheless, the tone remained, and geometric constraints limited the degree to which the combustor length could be further altered.

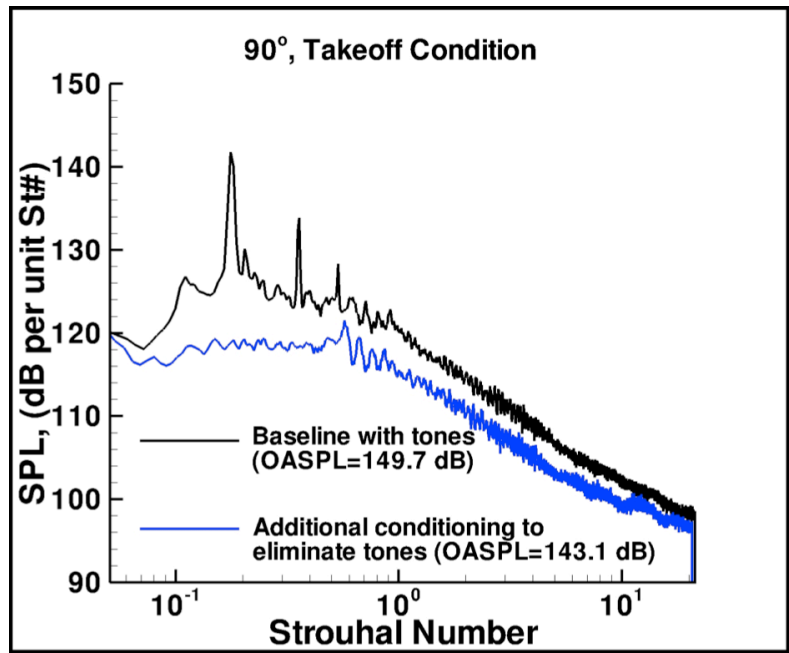

a)

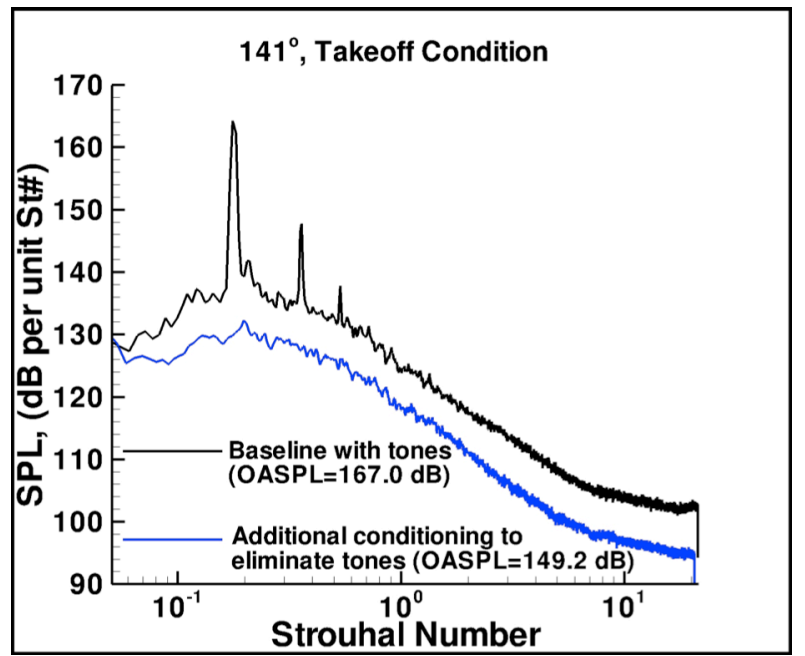

b)

Figure 10. Far-field acoustic spectra with core stream operating at takeoff condition $\left(N P R_{\text {core }}=1.411\right.$, $N T R_{\text {core }}=2.958, M_{w t}=0.10$ ) and fan stream providing minimal cooling air showing dominant combustion-driven acoustic instability tones and their elimination at microphone polar angles of a) $90^{\circ}$ and b) $141^{\circ}$. Strouhal number nondimensionalization is with respect to core stream in this case. 
Several modifications to the fuel delivery system (pressure, temperature, and symmetry) were investigated without success. Furthermore, introducing asymmetries along the axis of the combustor liner with tabs or bumps also proved unsuccessful. Progress was made in modifying the downstream flow conditioner with significant surface variation, as shown in Fig. 11, to allow the nonuniform impedance to break up the reflected acoustic wave; however, the tone amplitude was only reduced, not eliminated. Finally, a perforated screen was also added just upstream of the swirl cavity to change the effective length of the combustor. The nonuniform downstream flow conditioner together with the perforated screen upstream flow conditioner effectively eliminated the tones, as can be seen by the second set of spectra in Fig. 10. While either change alone reduced the tones, both changes were required to remove the tones from the spectra. In optimizing this arrangement, it was found that the concave flow conditioner shown in Fig. 11c and a Dynapore High Flow Media HFM 600 screen with several 0.122" diameter drilled holes (resulting in an additional porosity of approximately 15\%) were the best combination. Figure 12 shows this added hardware in blue. This combination was used to generate the second set of spectra in Fig. 10 (although with a slightly less porous $11 \%$ disk). It should be noted that there are additional broadband benefits noticeable in Fig. 10 due to some acoustic modifications in the fan stream that took place after the baseline measurements, and these modifications will be further discussed. Interestingly, the effects of the modifications are noticeable even when running only minimal fan stream cooling air.

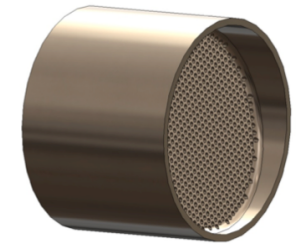

a)

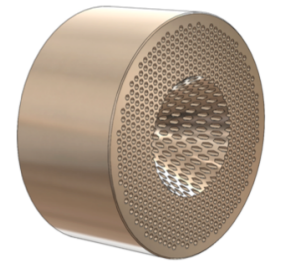

c)

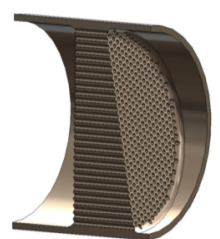

)

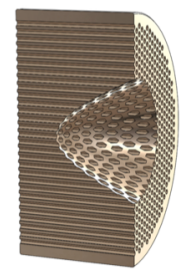

(1)

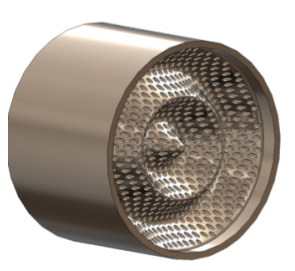

b)

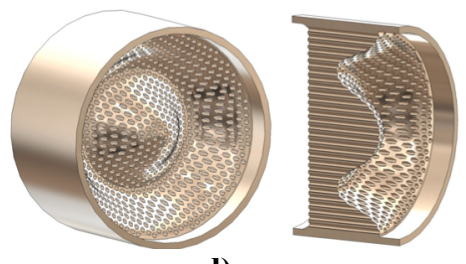

d)

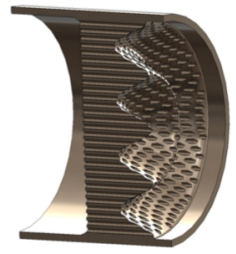

Figure 11. Laser-sintered core downstream flow conditioners for breaking up acoustic resonance with surface variations including a) bevel, b) sine of revolution, c) concave and d) cosine of revolution. All flow conditioners have a 1.5" maximum thickness.

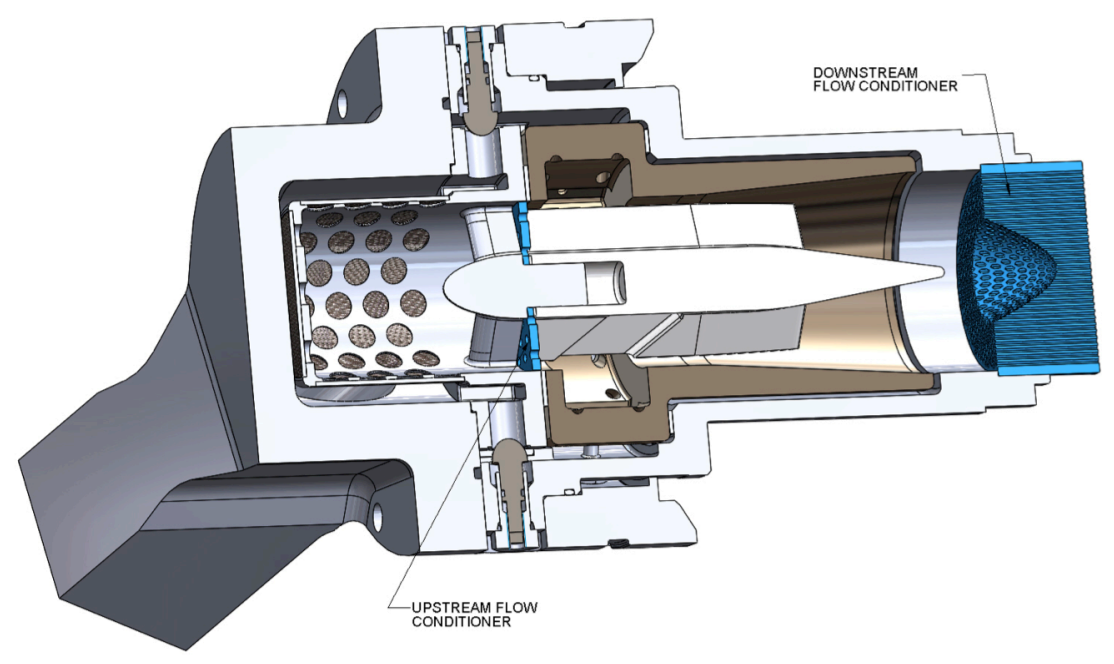

Figure 12. Schematic UCC including nonuniform downstream flow conditioner and perforated screen upstream flow conditioner used together to eliminate combustion instability tones. 


\section{Toward Minimal Rig Noise}

The elimination of the combustion instability tones lowered the jet spectral levels revealing other rig noise issues of a more broadband nature. Also, the time spent diagnosing the core stream tones allowed the required modifications and pressure recertification of the fan stream supply line to proceed in parallel. Attaining full cycle point conditions in both streams was now possible. Qualitative assessments of spectra shapes and levels were made at various cycle conditions, and measurements were also made of the core and fan streams operating separately. Because the fan stream spectra overshadowed those of the core, the focus quickly turned to reducing rig noise in the fan stream, predominantly through the use of flow conditioners. Figure 13 and Table 2 document the efforts to further reduce CJES rig noise. Before discussing these efforts in great detail, it is important to understand why the fan stream presents the rig noise challenges that it does.

The fan or bypass stream delivers much more air than the core stream and at much lower temperatures. As the air is heated for a given Mach number setting, the density decreases, and the mass flow rate decreases. This leads to a decrease in the internal flow velocity within the rig. Therefore, core stream heating tends to help reduce rig noise as Viswanathan and $\mathrm{Czech}^{18}$ point out, assuming any combustion noise issues associated with heating have been properly addressed. With the bypass ratio 10 cycle for the current CJES experiments, a relatively low temperature fan stream with a mass flow rate of $7 \mathrm{lbm} / \mathrm{s}$ is typical, leading to potentially significant internal flow velocities. There are two additional challenges within the CJES design increasing the potential for rig noise from the fan stream. First, the turns in the delivery piping required to minimize frontal area in the wind tunnel flow can cause increased turbulence and noise. Second, the fan plenum cross-sectional area is only $40 \%$ bigger than the nozzle exit area, again to minimize frontal area and also to maintain realistic nacelle sizes. This plenum area is much smaller than one would design in a less-constrained environment, and can lead to significant internal flow velocity.

An example of the fan stream acoustic spectra without any downstream flow conditioner is shown as Configuration A in Fig. 13 and represents a starting point from which to reduce the fan noise. In fact, it proved difficult to even maintain the fan stream setpoint with no flow conditioner because of the swirling fan flow impacting the charging station. Configuration B adds a sintered screen flow conditioner to the fan stream as detailed in Table 2. Also note that the core stream uses the flow conditioner from Fig. 11b. The test point associated with this configuration, and all subsequent configurations, is heated and occurs after the resolution of the combustion instability issue. A dramatic broadband noise reduction is achieved by backpressuring the fan stream, reducing the rig velocity, and conditioning the flow as it exits the fan plenum. However, another rig noise source becomes apparent in the mid-frequency range of the spectrum.

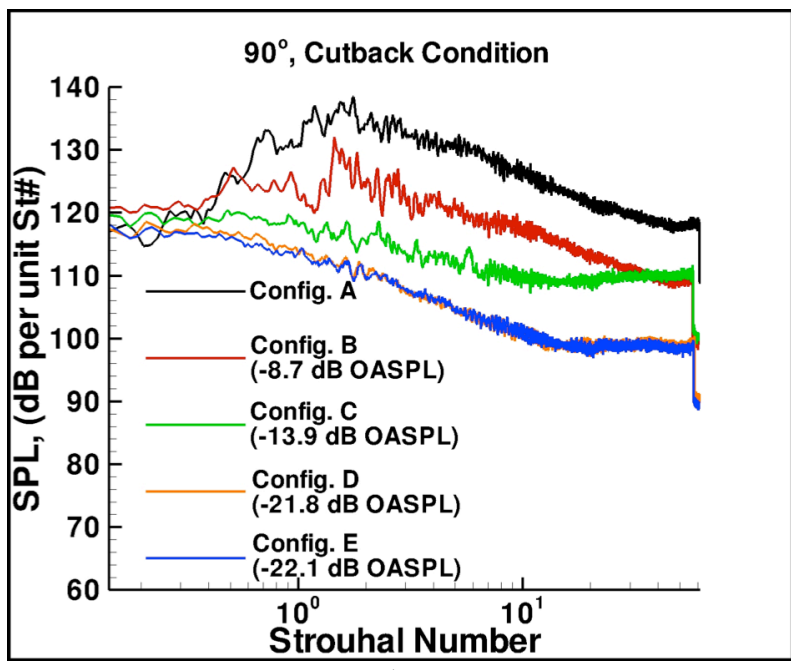

a)

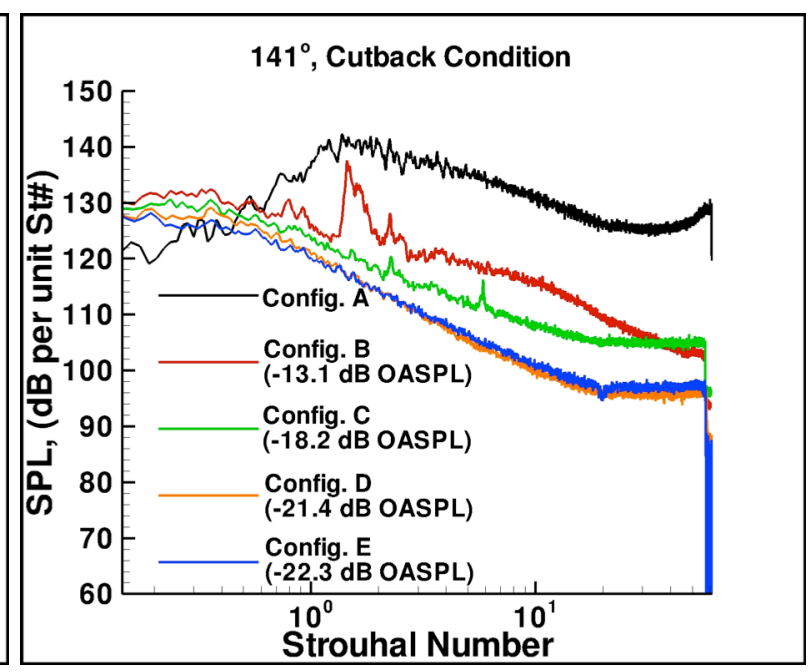

b)

Figure 13. Far-field acoustic spectra with CJES operating at original cutback condition: $N P R_{\text {core }}=1.285$, $N P R_{f a n}=1.508, N T R_{\text {core }}=2.792, N T R_{\text {fan }}=1.135, M_{w t}=0.10$ (except Config. A which was run at $N T R$ ' $s=1.00$ and no wind tunnel flow). Configurations demonstrating progressive rig noise reduction at microphone polar angles of a) $90^{\circ}$ and b) $141^{\circ}$. 
Table 2. Configuration details for rig noise reduction.

\begin{tabular}{|c|c|c|c|}
\hline Configuration & Core downstream FC & Fan downstream FC & Further comments \\
\hline $\mathrm{A}$ & $\begin{array}{l}\text { 11.6 POA honeycomb, } 0.5 " \\
\text { thick }\end{array}$ & None & $\begin{array}{l}\text { Unheated run with no } \\
\text { wind tunnel flow }\end{array}$ \\
\hline B & $\begin{array}{c}\text { Sine of revolution with } \\
\text { initial HFM } 600 \text { upstream } \\
\text { disk }\end{array}$ & $\begin{array}{l}\text { Dynapore HFM } 600 \text { sintered } \\
\text { screen on downstream side of FC, } \\
0.065 \text { " thick }\end{array}$ & $\begin{array}{l}\text { Combustion } \\
\text { instability tones } \\
\text { already eliminated }\end{array}$ \\
\hline $\mathrm{C}$ & $\begin{array}{l}\text { Sine of revolution with } 15 \% \\
\text { HFM } 600 \text { upstream disk }\end{array}$ & $\begin{array}{l}\text { Same as Config. B with additional } \\
120^{\circ} \text { arc of HFM } 600 \text { on upstream } \\
\text { side of flow conditioner, } 1.37 \text { "gap } \\
\text { in between screen sections }\end{array}$ & $\begin{array}{l}\text { Fan inlet piping with } \\
\text { bends removed, } 70 \\
\text { POA honeycomb fan } \\
\text { inlet flow conditioner }\end{array}$ \\
\hline $\mathrm{D}$ & Same as Configuration $\mathrm{C}$ & $\begin{array}{l}\text { 16.5 POA honeycomb, } 0.5 \text { " thick + } \\
\text { 1" gap + Dynapore DP450661 fine } \\
\text { sintered screen, } 0.018 \text { " thick }\end{array}$ & $\begin{array}{l}\text { High temperature } \\
\text { silicone seal around } \\
\text { exterior of charging } \\
\text { station and around } \\
\text { core/fan flow } \\
\text { conditioner } \\
\text { upstream/downstream } \\
\text { faces }\end{array}$ \\
\hline $\mathrm{E}$ & $\begin{array}{c}\text { Concave with } 15 \% \text { HFM } \\
\text { upstream disk }\end{array}$ & Same as Configuration D & Best case \\
\hline
\end{tabular}

To explore further fan flow conditioner modifications, Configuration $\mathrm{C}$ includes a second stage of sintered screen on the upstream side of the fan flow conditioner. This screen spans a $120^{\circ}$ arc along the bottom of the flow conditioner in an attempt to further backpressure the flow as it pours into the bottom of the fan plenum. The intent is to redirect more of the flow around the top of the annulus to encourage uniformity. Nonetheless, the increased backpressure made it difficult to achieve the fan stream setpoints, and a further inlet piping modification was necessary. Two $90^{\circ}$ bends were eliminated from the fan stream inlet piping, and the supply air hose was mated directly with the fan inlet feed pipe to the fan plenum. As can be seen in Fig. 13a and 13b, the noise from this pipe configuration was responsible for the large mid-frequency peak previously mentioned, judging from the disappearance of the peak when going from Configuration B to Configuration C. Unfortunately, the removed turning pipe is required for the $14 \times 22$ test in order to fit the CJES units into their shrouds. Therefore, additional honeycomb flow conditioners were manufactured for placement downstream of the turning pipe for use in the $14 \times 22$ test. One such flow conditioner was also used in the current configuration. The increased supply pressure limits of the $14 \times 22$ setup provide flexibility for a range of inlet pipe flow conditioners to hopefully mitigate what has been shown to be a noticeable noise source.

Configuration D achieves further significant noise reduction, mostly at the highest frequencies, by replacing the fan downstream flow conditioner with a $16.5 \mathrm{POA}$ honeycomb/fine screen combination as noted in Table 2. The 
reduced porosity further slows the velocity through the rig, and the fine sintered screen Dynapore DP450661 helps reduce any self-noise from the holes of the honeycomb. An earlier CJES risk reduction study ${ }^{11}$ had also identified this flow conditioner arrangement as an optimal candidate for further testing. In addition to the flow conditioner change, the CJES unit was sealed with high temperature silicone sealant around the exterior charging station mating surface and on the fore and aft edges of both the fan and core downstream flow conditioners. This step was taken because some leaking between fan and core streams was indicated, both by the charging station instrumentation measurements and small occasional tones in the acoustic spectra. Lastly, Configuration E exchanges the core downstream flow conditioner of Fig. 11b with the concave version shown in Fig. 11c to achieve only slight further improvement.

Figure 13 summarizes a few key configurations in the efforts to minimize CJES rig noise. There were numerous additional configurations and modification details that are beyond the scope of this discussion. While reduction of rig noise was the primary goal of all the modifications described, another important element to consider is the effect of the flow conditioner (or other flow path modifications) on the flow distribution.

Figure 14 shows the pressure and temperature distributions for Configuration $\mathrm{E}$ at the takeoff condition superimposed onto a charging station schematic. The core stream pressure ports in Fig. 14a are within less than 1 psia of each other, whereas the fan stream pressure port range is 3.3 psia. The fan stream pressure distribution tends to favor the inner and outer walls of the annulus. The temperature distributions are shown in Fig. 14b. As expected, the electrically-heated fan stream temperatures are fairly uniform, within $5.6^{\circ} \mathrm{R}$, while the core stream distribution has a much larger range of approximately $187^{\circ} \mathrm{R}$. The temperatures near the outer walls of the core stream tend to be higher than along the centerline. Note that these distributions are not as uniform as might be expected from a conventional jet rig. However, comparisons of acoustic spectra with the charging station rotated to different azimuthal positions do not show notable differences. The distributions with this set of flow conditioners are among the best observed for this compact rig in which the axial distance between the charging station rakes and the fan supply pipe centerline is only 4.5 inches, and the axial distance between the charging station rakes and the fuel injector ports is only 8.4 inches.

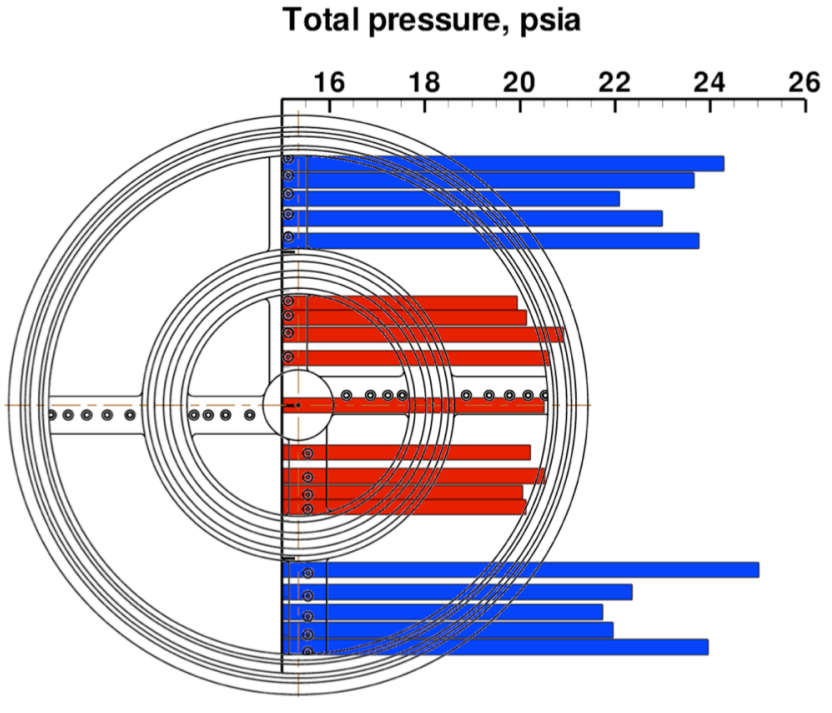

a)

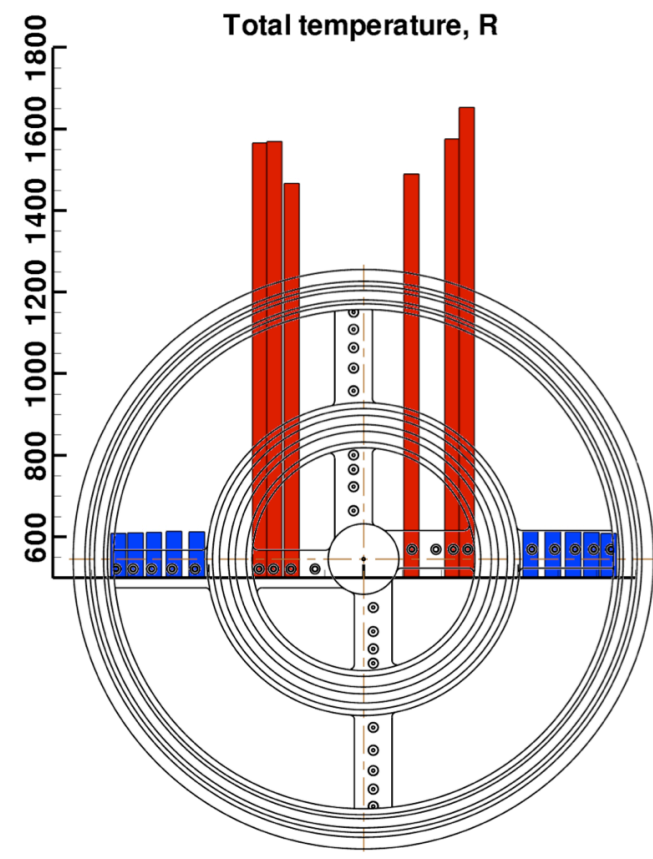

b)

Figure 14. Charging station a) pressure and b) thermocouple rake distributions for CJES unit operating at takeoff condition: $N P R_{\text {core }}=1.411, N P R_{\text {fan }}=1.607, N T R_{\text {core }}=2.956, N T R_{\text {fan }}=1.161, M_{w t}=0.10$. (Two core thermocouples were not functioning for this test.) 
Figures 13 and 14 demonstrate the degree to which Configuration $\mathrm{E}$ reduces rig noise and maintains flow uniformity. A more quantitative sense of how well the CJES unit represents jet noise is exhibited in Fig. 15. In this case, the one-third octave equivalent data of Configuration E in Fig. 13 are compared to the same setpoint run at Boeing's Low Speed Aeroacoustic Facility (LSAF) during the experimental investigation described in Thomas et $a l .{ }^{12}$ The efforts to reduce rig noise at the larger scale LSAF are noteworthy ${ }^{1,7}$, thus offering a rigorous comparison for the CJES evaluation. Spectra in the mid-frequency range match very well, particularly in the upstream arc. However, at low frequencies CJES values are 2-3 dB lower than the LSAF results. This discrepancy could be due to the large fuel valve pallet required for testing the CJES unit and the associated wedge covering used in LSAWT. This obstruction was on the microphone side of the chamber and could have disrupted or partially shielded the downstream low frequency acoustic source propagation. In addition, the LSAF data includes the use of a vacuum pump-driven boundary layer bleed system, which means that the external boundary layer over the fan nozzle was reduced compared to that over the CJES. Also, the potential for pump noise contamination at upstream angles is possible and likely the reason for the low frequency upward trend in the LSAF data at $50^{\circ \#}$.

More concerning, however, are the 5-10 dB increases in the CJES spectra at the highest frequencies. This behavior is consistent with the "flattening out" of the narrowband spectra that can be observed in Fig. 13 and is usually an indication of rig noise. In fact, the behavior of the spectra at high frequency looks very similar to the high frequency lift observed from self-noise of honeycomb flow conditioners ${ }^{11}$ before a fine screen is placed downstream. In those previous cases, the DP450661 fine screen was always sufficient to attenuate upstream noise from the perforate plate and shift any self-noise to frequencies beyond interest. However, the previous study was at a much lower scale with lower mass flow rates and a straighter flow path than the CJES unit.

Extensive efforts were made to further improve the high frequency spectra by altering the fan flow conditioner arrangement. Flow conditioner rings without the honeycomb portion, with other honeycomb porosities, and with multiple stages of DP450661 fine screen were tried, to name a few. These modifications required off-site precision E-beam welding to ensure the 0.018 " fine screen could withstand the anticipated pressure differential, often in excess of 200 psia at high setpoints. However, none of these modifications to date have shown further high frequency noise reduction beyond Configuration E. A larger fan stream plenum area and a more gradual fan stream entry angle are possible design modifications for future CJES improvements.

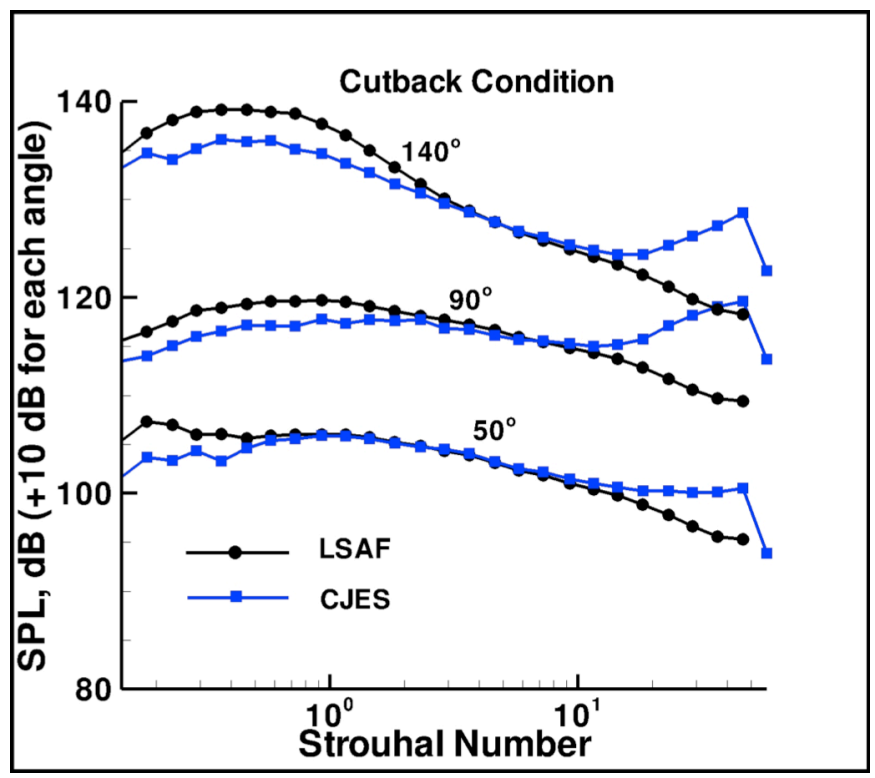

Figure 15. Far-field one-third octave acoustic spectra with CJES and LSAF operating at nominal original cutback condition: $N P R_{\text {core }}=1.285, N P R_{\text {fan }}=1.508, N T R_{\text {core }}=2.792, N T R_{\text {fan }}=1.135, M_{w t}=0.10$. A $10 \mathrm{~dB}$ addition to $90^{\circ}$ spectra and a $20 \mathrm{~dB}$ addition to $140^{\circ}$ spectra were applied to better visualize the data, as is the case for the remaining spectral figures.

\footnotetext{
\# Private communication with Michael Czech, March 28, 2013
} 


\section{Isolated Benefits of Chevron Nozzle}

The CJES results presented thus far have all been associated with an axisymmetric core and fan nozzle system. These nozzles serve as the baseline set for the HWB acoustic test. An additional low-noise nozzle set was downselected from extensive testing described in Thomas et al. ${ }^{12}$ The main objective of that work was to design an optimum low-noise bypass ratio 10 nozzle set for the HWB acoustic test. The best low-noise candidate from that test was an essentially uniform core chevron nozzle coupled with a circumferentially varying fan chevron design that built upon prior efforts that included pylon effects studies ${ }^{8}$. The longest chevrons in the asymmetric design are oriented away from the ground observer to minimize high frequency penalties. This effect, combined with the low frequency noise benefit provided by traditional chevrons, produces a noise benefit in isolated nozzle testing.

Furthermore, the chevron nozzle system provides for a peak noise source redistribution toward the upstream direction to enhance any potential shielding benefits for an installed jet configuration. Because the nozzle set tested at LSAF required slight design modifications to chevron geometry prior to the fabrication of the CJES-scale nozzles, and because the nozzle set had not been tested with the CJES, an objective of the current study is to assess/verify the noise reduction potential for the low-noise nozzle concept on the CJES in an isolated jet environment in LSAWT. The chevron nozzle set can be seen on the CJES in Fig. 2.

Figure 16 shows the benefits of the chevron design on the CJES at the updated cutback cycle point. It should be noted that for these studies the core flow conditioner downselection had not been finalized so all data includes the sine of revolution core downstream flow conditioner shown in Fig. 11b. In Fig. 16 the asymmetric nozzles were rotated to the flyover orientation (nozzle 12:00 position at $180^{\circ}$ to the linear microphone array). A benefit of over 3 $\mathrm{dB}$ at low frequencies is observed relative to the axisymmetric baseline nozzle set as seen in Fig. 16a. In addition, a noise benefit extends throughout the polar directivity range denoted in Fig. 16b. While a small high frequency noise penalty is expected, it is less noticeable due to the high frequency noise increases of the CJES previously discussed.

Further investigation at the takeoff configuration is shown in Fig. 17. The nozzle set was rotated to the sideline orientation (nozzle 12:00 position at $120^{\circ}$ to the linear microphone array). Once again a low frequency noise benefit of 2-3 dB is typically observed. This result is consistent with what was observed in the testing at LSAF described in Thomas et al. ${ }^{12}$ Figure 13 from that work shows similar benefits at the same run condition, albeit with a higher flight stream Mach number. The consistent performance of the low-noise nozzle concept on the CJES builds confidence for the HWB acoustic test in which the full noise benefits with shielding effects can be realized.

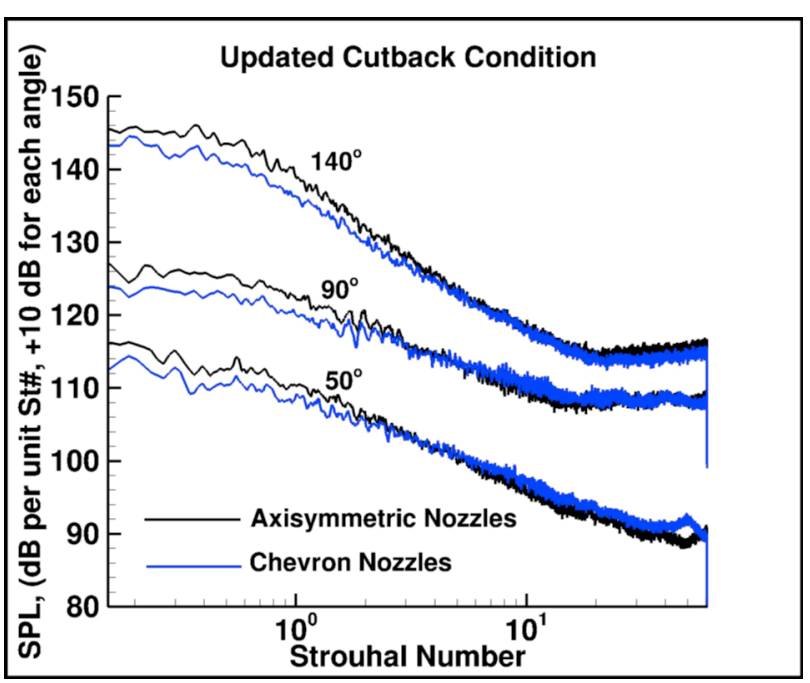

a)

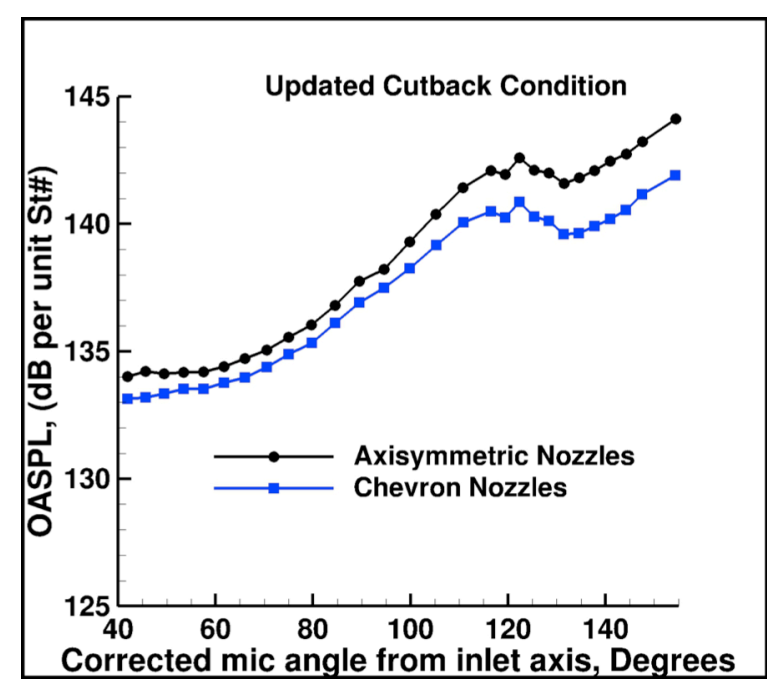

b)

Figure 16. Far-field acoustic spectra with CJES operating at updated cutback condition: $N P R_{\text {core }}=1.240$, $N P R_{f a n}=1.461, N T R_{\text {core }}=2.721, N T R_{f a n}=1.124, M_{w t}=0.10$ showing a) spectral and b) directivity benefits of the chevron design. 


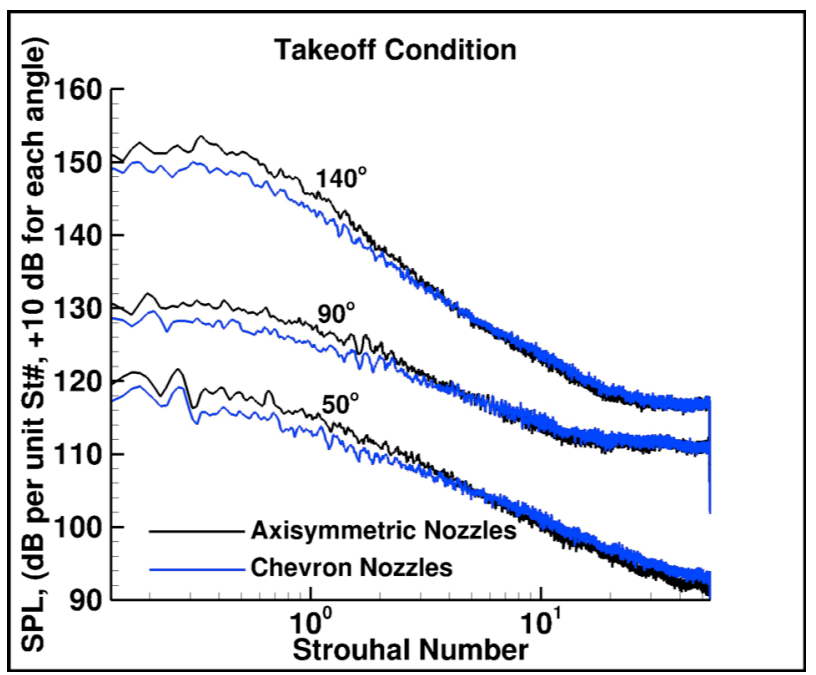

a)

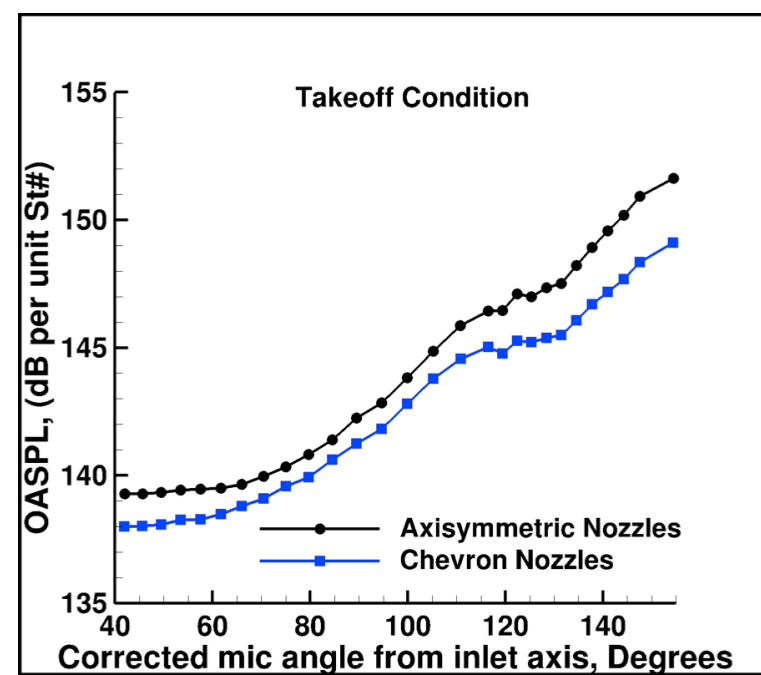

b)

Figure 17. Far-field acoustic spectra with CJES operating at takeoff condition: $N P R_{\text {core }}=1.411, N P R_{\text {fan }}=1.607$, $N T R_{\text {core }}=2.956, N T R_{f a n}=1.161, M_{w t}=0.10$ showing a) spectral and b) directivity benefits of chevron design.

\section{Consistency between CJES Units}

Prior to the HWB acoustic test that uses two CJES units, it is important to check for a consistent noise signature between the units so as not to be misled during the jet shielding and interaction studies. Therefore, each CJES unit was tested independently with its own set of hardware. The only notable exceptions were the downstream core and fan flow conditioners. The Configuration D (see Table 2) flow conditioners were used for the core and fan streams, but spares had not yet been manufactured. Therefore, the same common flow conditioners were used in each CJES unit.

Figure 18 shows the consistency between the two separate units tested over a month apart as two different simulator build-ups, both using axisymmetric nozzles. The spectral comparisons are quite close with the exception of a mid-frequency difference between units at aft angles that is still under investigation as shown in Fig. 18a. Similarly, the directivity comparison of Fig. $18 \mathrm{~b}$ shows consistency within $0.5 \mathrm{~dB}$ OASPL, providing confidence for consistency in further HWB testing.

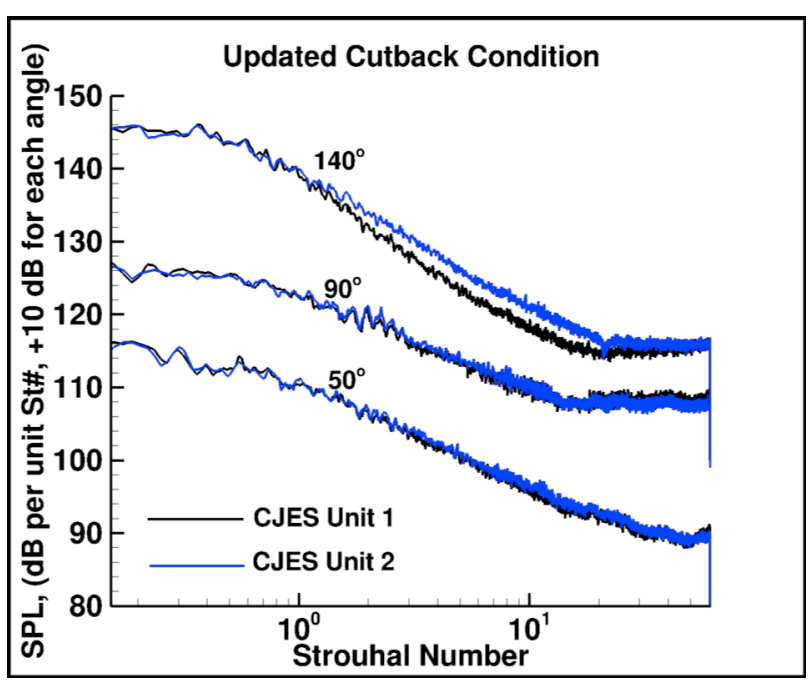

a)

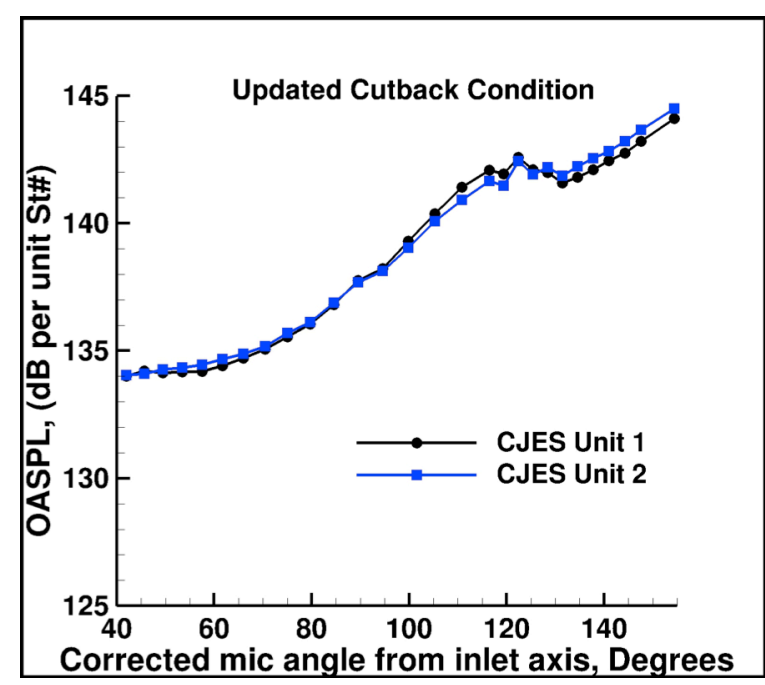

b)

Figure 18. Far-field acoustic spectra with axisymmetric nozzles and CJES operating at updated cutback condition: $N P R_{\text {core }}=1.240, N P R_{\text {fan }}=1.461, N T R_{\text {core }}=2.721, N T R_{f a n}=1.124, M_{w t}=0.10$ showing a) spectral and b) directivity differences between CJES units. 


\section{Concluding Remarks}

This paper characterizes the acoustic and aerodynamic properties of two dual-stream, heated jet, Compact Jet Engine Simulator (CJES) units prior to use in the Hybrid Wing Body (HWB) acoustic test within the 14-by 22-Foot Subsonic Tunnel at NASA Langley Research Center. To maintain consistency with a 5.8\% HWB model, the CJES design has to be significantly smaller than conventional jet engine simulators, presenting many potential implementation and rig noise issues. The smaller design is made possible, in large part, by the adaptation of Ultra Compact Combustor (UCC) technology developed at the Air Force Research Laboratory.

Both the UCC and the full CJES units are operated in the Low Speed Aeroacoustic Wind Tunnel. First, stable combustion is established in the UCC after pressure surveys within the combustor swirl cavity establish the proper swirl air valve settings and the need for a sealed combustion liner free of significant cracks. Second, controllability of the combustor flow is shown by properly backpressuring the chamber with a core downstream flow conditioner.

The build-up and acoustic testing of the full CJES unit shows a combustion-driven acoustic instability that initially dominates the far-field noise spectra with tones in excess of $25 \mathrm{~dB}$ above broadband levels. Ultimately, the switch to a flow conditioner with a nonuniform face coupled with the addition of a perforated screen disk just upstream of the swirl air cavity is sufficient to break up the acoustic resonance, thus eliminating the tones. Efforts then focus on minimizing the rig noise from the CJES unit. A series of configuration changes, mostly to the fan downstream flow conditioner demonstrates over $20 \mathrm{~dB}$ of rig noise reduction over a broad frequency range. Nonetheless, some level of increased high frequency noise remains in the fan stream, as shown in comparisons with data at the same cycle point from Boeing's Low Speed Aeroacoustic Facility (LSAF).

Comparisons are made between the axisymmetric nozzle set and a low-noise chevron nozzle set designed for implementation in the HWB acoustic test. These results show low frequency reductions of 2-3 dB consistent with previous tests at LSAF. Lastly, an assessment of the consistency of noise spectra between the two CJES units shows similar spectral behavior and directivity levels within 0.5 OASPL.

\section{Acknowledgments}

The authors sincerely thank the Environmentally Responsible Aviation Project for funding this work. The efforts of the Jet Noise Lab technical staff (John Swartzbaugh, Shaun Reno, Clint Reese, Butch Allen, and Mike Carr) are gratefully acknowledged. Additionally, the authors thank Les Yeh, Mark Carpenter, and Mike Henshaw for CJES control implementation, and Governor's School student Megan Beisser for her assistance in the swirl velocity measurements. Lastly, the authors acknowledge the excellent support of the NASA Langley Research Center fabrication and welding services, as well as the welding services of Bill Clemens at the Thomas Jefferson National Accelerator Facility. The Compact Jet Engine Simulator is U.S. Patent Pending.

\section{References}

${ }^{1}$ Viswanathan, K., "Jet Aeroacoustic Testing: Issues and Implications,” AIAA Journal, Vol. 41, No. 9, September 2003, pp. 1674-1689.

${ }^{2}$ Soeder, R., Wnuk, S., and Loew, R., "Aero-Acoustic Propulsion Laboratory Nozzle Acoustic Test Rig User Manual," NASA/TM-2006-212939, 2006.

${ }^{3}$ Thomas, R. H., and Kinzie, K. W., "Jet-Pylon Interaction of High Bypass Ratio Separate Flow Nozzle Configurations," AIAA Paper No. 2004-2827 presented at the 10 ${ }^{\text {th }}$ AIAA/CEAS Aeroacoustics Conference, May 2004.

${ }^{4}$ Harper-Bourne, M., "Commissioning and Validation of a New Jet Rig for the QinetiQ Noise Test Facility," AIAA Paper No. 2008-2958 presented at the $14^{\text {th }}$ AIAA/CEAS Aeroacoustics Conference, May 2008.

${ }^{5}$ Piccin, O., "CEPRA19: the ONERA large anechoic facility," AIAA Paper No. 2009-3303 presented at the 15 ${ }^{\text {th }}$ AIAA/CEAS Aeroacoustics Conference, May 2009.

${ }^{6}$ Ahuja, K. K., "Designing Clean Jet-Noise Facilities and Making Accurate Jet-Noise Measurements," Int. Journal of Aeroacoustics, Vol. 2, No. 3\&4, 2003, pp. 371-412.

${ }^{7}$ Viswanathan, K., "Best Practices for Accurate Measurement of Pure Jet Noise," Int. Journal of Aeroacoustics, Vol. 9, No. 1\&2, 2010, pp. 145-206. 
${ }^{8}$ Czech, M. J., Thomas, R. H., and Elkoby, R. "Propulsion Airframe Aeroacoustic Integration Effects of a Hybrid Wing Body Aircraft Configuration,” International Journal of Aeroacoustics, Vol. 11, No. 3+4, 2012, pp. 335-368.

${ }^{9}$ Zelina, J., Ehret, J., Hancock, R. D., Shouse, D. T., Roquemore, W. M., and Sturgess, G. J., "Ultra-Compact Combustion Technology Using High Swirl For Enhanced Burning Rate," AIAA Paper No. 2002-3725 presented at the $38^{\text {th }}$ AIAA/ASME/SAE/ASEE Joint Propulsion Conference and Exhibit, July 2002.

${ }^{10}$ Lewis, G. D., "Centrifugal-Force Effects on Combustion," Proceedings of the $14^{\text {th }}$ Symposium on Combustion, the Combustion Institute, 1973, pp. 413-419.

${ }^{11}$ Doty, M. J., and Haskin, H. H., "Investigation of Flow Conditioners for Compact Jet Engine Simulator Rig Noise

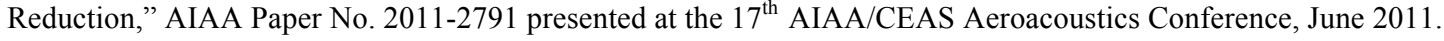

${ }^{12}$ Thomas, R. H., Czech, M. J., and Doty, M. J., "High Bypass Ratio Jet Noise Reduction and Installation Effects Including Shielding Effectiveness," AIAA Paper No. 2013-0541 presented at the 51 ${ }^{\text {st }}$ AIAA Aerospace Sciences Meeting, January 2013.

13"Method for the Calculation of the Absorption of Sound by the Atmosphere," ANSI S1.26-1978, (ASA 23-1978), American Nat. Stand. Inst., Inc., June 23, 1978.

${ }^{14}$ Amiet, R. K., "Refraction of Sound by a Shear Layer,” Journal of Sound and Vibration, Vol. 58, No. 3, 1978, pp. 467-482.

${ }^{15}$ Zelina, J., Sturgess, G. J., Mansour, A., and Hancock, R. D., "Fuel Injection Design Optimization For An Ultra-Compact Combustor," ISABE Paper No. 2003-1089 presented at the $16^{\text {th }}$ International Symposium on Air Breathing Engines, September 2003.

${ }^{16}$ Zelina, J., "High Gravity (g) Combustion,” AFRL-PR-WP-TR-2006-2079 Final Report, February 2006.

${ }^{17}$ Eisinger, F. L., and Sullivan, R. E., “Avoiding Thermoacoustic Vibrations in Burner/Furnace Systems,” Transactions of the $A S M E$, Vol. 124, November 2002, pp. 418-424.

${ }^{18}$ Viswanathan, K., and Czech, M. J., "Role of Jet Temperature in Correlating Jet Noise," AIAA Journal, Vol. 47, No. 5, May 2009, pp. 1090-1106. 